\title{
A NOCIÓN DO POÉTICO EN CUNQUEIRO
}

\author{
Manuel Forcadela \\ Universidade de Vigo \\ doi:10.17075/mucnoc.2014.022
}



Forcadela, M. / T. López / D. Vilavedra (coords.) (2014): Mil e un cunqueiros. Novas olladas para un centenario, Santiago de Compostela, Consello da Cultura Galega. doi:10.17075/mucnoc.2014. pp. 447-464

\section{O AUTOR COMO CONSTRUTO SOCIOLÓXICA}

O primeiro que debemos sinalar, antes de entrarmos na análise pormenorizada (aínda que non todo o que debésemos) dalgunhas das peculiaridades da poética de Cunqueiro, é a nosa principal, e acaso controvertida, conxectura de partida: o autor é unha construto sociolóxica.

Entendemos que cada época sinala as regras dos xogos da interpretación literaria. Estas regras non son fixas e están sometidas ás flutuacións das décadas e dos anos, aos abalos e devalos das modas teóricas, ás mareiras dos intereses ideolóxicos que a miúdo subxacen nestas oscilacións. Nos case trinta anos que levamos dedicándonos ao estudo e ao ensino da literatura, en xeral, e da literatura galega, en particular, temos visto desfilar perante os nosos ollos unha sucesión de modelos analíticos e interpretativos. Todos eles teñen dado os seus froitos á hora de entender a obra de A. C. Desde o formalismo aínda estruturalista da universidade en que nos formamos, até a estética da recepción, pasando pola mitocrítica, a psicoanálise, os diferentes modelos marxistas, a historia da crítica de Cunqueiro é, como dicimos, ben significativa neste sentido. Revélanos en que medida pasamos dun A. C. lido en clave antropolóxica e mitocrítica durante os anos oitenta e anteriores (GarcíaSabell, Salvador Lorenzana, Martínez Torrón, Pérez-Bustamante...), a un A. C. lido en clave estruturalista e narratolóxica nos anos noventa (González Millán, Rexina R. Vega, Dolores Vilavedra...) para chegarmos finalmente a unha lectura en clave ideolóxica a finais desta última década (Spitzmesser, Rivera Pedredo, eu mesmo...). Así pois, pasamos en poucos anos da celebración de A. C. como unha especie de derradeiro chamán de Occidente, insistindo nas pautas de celtismo, sociedade arcaica, narración oral, etc., a un A. C. narrador heterodoxo que quebra as regras da narración convencional e sitúase no mesmo centro do interese das investigacións narratolóxicas, para chegarmos finalmente a un A. C. construtor dun mundo de ficcións que non son máis que a interiorización sublimada da represión política do franquismo tal e como foi captada por el ao longo da súa existencia, pero tamén un A. C. posmoderno, deconstrutor de mitos. 
Vemos, polo tanto, como a construción de A. C. vaise levando a cabo pouco e pouco a medida que as diferentes épocas e os diferentes modelos críticos e interpretativos se van sucedendo e establecendo lecturas e interpretacións que non foran supostas nin polo autor real nin polo seu tempo, pero que estaban implícitas na propia semiose dos seus textos. E a canonización de A. C. obedece tamén a esta versatilidade das súas prácticas textuais. $\mathrm{O}$ feito de que en calquera dos casos se saúde a A. C. como un clásico, como un autor definitivamente pertencente ao panteón dos grandes autores e autoras da tradición literaria galega sinala non só a súa forza (force, Moreiras 2001), a súa potencialidade, senón tamén o seu poder (power), a súa primacía xa consolidada dentro do canon galego contemporáneo.

E entendemos que os poucos anos que levamos de século Xxi foron testemuñas senón da emerxencia si da consolidación do que poderiamos denominar modelos sociolóxicos, tanto na súa vertente Bourdieu como na súa vertente Itamar Even Zohar, tanto nas vertentes poscoloniais como na vertente de crítica da ideoloxía ou dos denominados estudos culturais (cultural studies), etc., encadrables todas elas dentro do que podemos denominar crítica da sospeita ou do que Harold Bloom (1995) denomina "escola do resentimento». Quérese dicir que estes anos do capitalismo serodio ou do poscapitalismo ou como lle queiramos chamar semellan estarnos a revelar, tanto desde o punto de vista da teoría crítica como desde o comportamento dos poderes culturais, a importancia, a relevancia política da ficción, sexa esta literaria ou non. Concluíndose, polo tanto, que non hai autor sen sociedade, e que a presenza desta naquel é indispensable, da mesma maneira que non hai viño sen auga, aínda que, habitualmente, convencionalmente, a escolla entre viño e auga sexa mutuamente exclusiva. Pois todo o mundo sabe que unha análise de calquera viño nos revela a presenza dunha elevadísima porcentaxe hídrica. 


\section{A HISTORIA DA LITERATURA COMO RELATO E COMO PERCO- RRIDO NARRATIVO CANÓNICO}

Imponse, polo tanto, segundo a lóxica dos tempos, unha lectura de Cunqueiro que nos permita entender, desentrañar, en que medida a sociedade que o acompañou ao longo do tempo da súa existencia e as sociedades que posteriormente seguiron frecuentando as súa obras están representadas nestas e aspiran a sublimar nelas algunha das súas carencias. E velaí a ficción autor A. C. Obviamente, esta representación das sociedades posteriores ao autor real e ao seu tempo de existencia só pode darse no caso de que admitamos que ese A. C. do que estamos a falar pouco ou nada ten a ver co autor real e moito ou todo coa súa proxección fantasmática sobre a historia da nosa cultura. Temos, pois, que distinguir claramente entre o que imos denominar autor real e o que denominaremos ficción autor. Entendemos que a historia da literatura é un relato, ao xeito dun longo roman-fleuve, no que os personaxes non son outros que estas ficcións de autor das que estamos a falar. E que son as propias condicións dese relato as que acaban deturpando o propio relato e a súa relación cos feitos verdadeiramente acontecidos. O crítico, polo tanto, contribúe a ese roman-fleuve e tamén se ve afectado por el. Velaí o que a historia da literatura ten de gran ficción nacional. Velaí o que a historia da literatura ten necesariamente de nacional, sexan cales foren os autores e as nacións. E son tantos os imponderables de natureza ideolóxica que xorden no camiño que dificilmente pode haber unha intromisión nese relato que se poida afastar do que Greimas denominou no seu día «percorrido narrativo canónico». A historia da literatura é, como temos tentado demostrar (2008), un relato dos feitos da nación, considerados agora non desde a perspectiva das armas ou das guerras, das conquistas e das vitorias, senón desde a perspectiva dos logros no terreo da expresión e das ideas. A historia da literatura é, polo tanto, a expresión dos méritos expresivos dun idioma, unha parte ben significativa do curriculum vitae dunha nación.

Hai, ademais, unha idea moi importante que debemos sinalar e que tamén contribúe a sinalar a importancia central deste relato: «o capital simbólico literario amoréase de xeito nacional» (Casanova). Dito noutras palabras: que unha tradición literaria exista e mesmo estea consolidada, até o punto de ofrecer autores como Cunqueiro e prácticas textuais como as que o fixeron famoso, é 
unha proba da nación, multitudinaria representación simbólica e imaxinaria erguida no decurso dos séculos e das xeracións.

Que esta construto pouco ou nada teña que ver co autor real (o individuo que algunha vez e durante varias décadas continuadas existiu realmente, comeu, bebeu, formouse, namorouse, tivo dous fillos, sobreviviu a unha guerra fratricida e á súa correspondente posguerra), senón que se institúa como un relato en que destaca un personaxe protagonista que coincide só co autor real na denominación que este escolleu para ser cońecido literariamente, obríganos a distinguir, polo tanto, entre o autor real (o individuo de carne e óso, nado en Mondoñedo en 1911 e morto en Vigo setenta anos despois) e a ficción autor (ese significante composto de nome e apelido, Álvaro Cunqueiro, que se vai enchendo de sentidos segundo pasan os anos, sentidos que podemos historizar e mesmo contrapor, xa que, en ocasións, chegan a ser contraditorios entre si) e que se institúe como o enunciador fantasmático de todos os seus discursos, o suxeito que subxace a cada unha das súas prácticas textuais e construído ao longo das décadas como unha entidade ficticia á que se pretende dar coherencia, sentido, á procura das súas causas mais tamén dos seus efectos.

\section{CUNQUEIRO COMO GRANDE AUTOR}

Cunqueiro, como se sabe, atravesou o tempo histórico da súa existencia en catro grandes etapas políticas que tiveron moito que ver co desenvolvemento da súa obra literaria. A etapa da II República spañola, que coincide co que en Galicia se denomina, desde o punto de vista da historiografía literaria, Período Nós; a Guerra Civil; a posguerra; o final da Ditadura e a transición política á Democracia. Téñense elaborado, cando menos, dous modelos tentando relacionar a súa creación literaria e o modelo político en que esta se levou a cabo: en primeiro lugar, o modelo de Ana Sofía Pérez Bustamante (1992) e, en segundo lugar, o de Ana María Spitzsmesser (1997). No primeiro dos modelos mencionados, a profesora gaditana sinala que (tradución nosa): 
Se atendemos á existencia ou non dun tempo máxico na fábula primordial, partindo da base de que sempre hai unha apertura ritual ao marabilloso, obtemos o seguinte:

+ tempo máxico
Merlín

Sochantre

Anos 50

Mundo marabilloso
- tempo máxico

Ulises

Sinbad

Orestes

Anos 60

Mundo ritual
+/- tempo máxico

Fanto

Cometa

Anos 70

Mundo fantástico

No segundo dos modelos, o enunciado pola profesora da Universidade de Niágara (tradución nosa):

Por esta razón, despois dunha carreira de escritor que durou varias décadas, a narrativa de Cunqueiro perde o compás, resultándolle imposible encontrar unha saída aceptable na nova realidade creada pola recuperación da liberdade. Aínda que sobreviviu ao Réxime seis anos, nunca logrou (a pesar de frecuentes declaracións de propósito) volver escribir outra novela.

\begin{tabular}{|c|c|c|}
\hline Forma política & Xénero preferente & Asociacións freudianas \\
\hline República & Poesía & Isto (principio do pracer) \\
\hline Guerra Civil & Xornalismo & Eu (principio da realidade) \\
\hline Posguerra & Narrativa & Súper Eu (principio da represión sobrante interiorizada) \\
\hline Democracia & & Vitoria do Súper Eu / Castración \\
\hline
\end{tabular}

Tentaremos explicar como esta fragmentación de A. C. en varias etapas, aínda sendo defendible e certa desde o punto de vista simplemente biográfico, non ten por que impedir ver o conxunto das súas prácticas textuais como unha peza unitaria, sometida, iso si, a determinadas tensións e flutuacións que queremos sinalar.

Entendemos que o crítico e o historiador literario traballan sobre dúas entidades igualmente fantasmáticas e inatinxibles, por máis que un sempre poida caer na 
tentación de pensar que isto non sexa así: a) o autor e b) a súa obra literaria ou, o que vén a ser igual, a) a ficción autor e b) as súas prácticas textuais.

Calquera tentación biografista ou referencialista carece de sentido desde esta perspectiva e o que asoma son as potencialidades semánticas que a obra e o autor seguen acollendo na súa semiose incesante, como verdadeiras máquinas de significar que, un ano despois doutro, haberán de recoller as colleitas diversas dos seus sentidos posibles, sexan cales foren os lectores por vir e os seus intereses ficcionais e ideolóxicos. Quere isto dicir que a relación entre o contexto político e social e a obra non ten porque ter unha relación de causa efecto, senón que, antes ben, o filtro da ficción, como o filtro dos soños de Freud, opera como un veo que torna metáfora e metonimia o que acaso puido instigar desde a realidade unha certa sublimación que remata por producir o texto e, sobre todo, a súa ficción. Situámonos, por tanto, nun terreo en que a indagación detallada da biografía do autor non reportará grandes avances xa que, en definitiva, o que nos interesa non é tanto a biografía externa das actualidades circunstanciais da vida do autor, senón máis ben esoutra biografía interna, da que as súas prácticas textuais son e serán sempre o mellor documento probatorio.

En resumo:

1. O autor non é unha construto estática, senón dinámica. A Álvaro Cunqueiro fáltanlle décadas e décadas de novas lecturas e recepcións.

2. Un autor é, sempre, unha expresión de conflitos. Nunca un equilibrio, un idilio verbal nin moito menos imaxinario.

3. O autor evoluciona e vai tendo idades, dinámicas que atravesan etapas.

4. Cada época bota man do autor para encontrar nel a súa verdade. Non tanto a verdade do autor como a verdade desa época.

Esta construto (o relato biográfico-crítico da ficción autor A. C.) artéllase ao redor de dous suxeitos predeterminados, que son a sociedade lectora e a tradición crítica, de maneira que podemos considerar que, fronte ao modelo psicoloxista de análise do suxeito creador, do genius evocado na obra horaciana («vultu mutabilis» Epistolas II.2.187.), do suxeito individualizado que leva a cabo a construción dunha obra nesa, radical e tópica, soidade do autor perante a folla de papel en branco ou fronte ao modelo formalista centrado na análise dunhas determinadas prácticas textuais, aparece estoutra maneira de achegármonos á obra (ás súas prácticas textuais) e ao autor desde unha perspectiva socioloxista, de análise da 
interrelación entre o suxeito creador, desaparecido en 1981, e a sociedade que establece un certo consenso valorativo e ideolóxico ao redor da súa obra. Feito e rematado o discurso de Cunqueiro, unha vez o autor real deixou definitivamente de escribir algún tempo antes da súa morte, é agora a tradición crítica a que debe construír o seu discurso tomando como obxectos de disertación tanto o propio A. C. como as súas prácticas textuais.

\section{CUNQUEIRO AUTOR BILINGÜE: VALOR E IDEOLOXÍA}

Non debemos esquecer que sobre os grandes autores sobrevoa sempre a posibilidade de consideralos excepcións. Isto significa retraelos desoutra construto que denominamos tradición, negándoa, esquecéndoa. $\mathrm{O}$ feito de que Cunqueiro escribise en dous idiomas (galego e castelán) e que só nun deles fose verdadeiramente vertebrado como un grande autor dá conta destes procesos sociais dos que falamos, e que máis abaixo rescataremos brevemente, e que nos dan conta da intraducibilidade do autor.

Valor e ideoloxía. Velaí os dous conceptos sobre os que tamén deberemos centrarnos. $\mathrm{O}$ valor en tanto que crenza, e a ideoloxía en tanto que consenso dun determinado momento histórico que permite que unha ficción literaria sexa considerada como lexible ou mesmo como clásica (exemplar e memorable) por parte dunha determinada sección dunha sociedade. $\mathrm{O}$ valor en tanto que valor simbólico, en realidade, isto é, como o valor suposto e xamais materializado que se lle atribúe a un autor en tanto que entidade fantasmática que pode darlle sentido e coherencia a unha obra, a un produto concreto dunhas determinadas prácticas textuais. Bourdieu fala, en realidade, de capital simbólico, entendendo por tal cousa certas propiedades que semellan inherentes ao propio axente cultural, neste caso o escritor, a autoridade, o prestixio, a reputación, o creto, a fama, a notoriedade, a honorabilidade, o bo gusto. O propio Bourdieu, que non emprega o concepto de ideoloxía, fala, en realidade, de habitus, por unha banda, e de doxa, por outra.

Cremos que A. C. é a vítima e, ao mesmo tempo, o protagonista dun grande episodio de violencia simbólica, un episodio que acontece ao mesmo tempo no mundo real do tempo que lle tocou vivir e no mundo dos sońos, no interior 
das súas ficcións literarias. Entre ese mundo real e esoutro mundo ficcional desenvólvese unha gran batalla que ten como único vencedor á morte, sempre vitoriosa, que leva finalmente consigo tanto a A. C. como ao tempo infame que lle cadrou en sorte como a tantos millóns de europeos, españois e galegos.

O combate de A. C. coa violencia simbólica e real do seu tempo non pode ser máis desigual. Recibe violencia e devolve soños. Este intercambio fálanos, no fondo, aínda que haxa quen poida botar man de datos biografistas e referencialistas para contradicir esta idea, da dimensión moral do personaxe. Mais tamén nos fala da importancia fundamental do imaxinario na construción da psique humana. Somos un soño, semella dicirnos A. C., como conclusión final a toda a súa obra. Somos o que sońamos e iso no ser humano, que vive na esperanza e cońece o futuro, é, sen dúbida, a clave da súa intimidade, da súa identidade. O ser humano real A. C., sometido ás vicisitudes máis crueis, afectado mesmo na súa dignidade, ameazado, secuestrado moral e intelectualmente, bótase a soñar, encontra o consolo da literatura e dá conta dunha das etapas de creatividade máis vizosas da nosa tradición contemporánea.

A noción de capital simbólico vai asociada tamén á noción de violencia simbólica, que se emprega para describir as formas de violencia non exercidas directamente mediante a forza física, senón a través da imposición por parte dos suxeitos dominantes aos suxeitos dominados dunha visión do mundo, dos roles sociais, das categorías cognitivas e das estruturas mentais. A violencia simbólica está, ademais, especialmente presente na literatura en tanto que toda ficción literaria é, por unha banda, o resultado dunha violencia simbólica e, pola outra, aspira a ser a sublimación desa violencia. O discurso literario non é máis que un dos discursos que interveñen na loita de discursos, no litixio entre enunciacións en que se converte o campo literario. A. C. aspira a adquirir capital simbólico nese campo, tanto dentro da tradición española como galega, no contexto histórico duns anos especialmente convulsos desde o punto de vista social e político. As súas prácticas textuais son claramente obxectos e suxeitos de violencia simbólica. Seguindo a J. Manuel Fernández (2005) no seu interesante artigo, o concepto de violencia simbólica desempeña un papel fundamental na análise da dominación en xeral feita por Pierre Bourdieu que a entende como un concepto insubstituíble para dar conta de fenómenos en aparencia tan distantes como a dominación persoal en sociedades tradicionais ou a dominación de clase nas sociedades 
avanzadas, as relacións de dominación entre nacións (como no imperialismo ou o colonialismo) ou a dominación masculina tanto nas sociedades primitivas como modernas. A dimensión simbólica, a autonomía e a dependencia relativa das relacións simbólicas en relación coas relacións de forza son tan importantes que negalas equivalería a «negar a posibilidade dunha ciencia sociolóxica».

\section{A ALUCINACIÓN COLONIALISTA DO AUTOR SEN TRADICIÓN}

Non debemos esquecer, ademais, que a relación entre, en primeiro lugar, esa sociedade lectora e, en segundo lugar, a tradición crítica e, finalmente, a ficción autor se constrúe de xeito múltiple, de maneira que podemos xulgar que unha determinada obra presupón un modelo de lector e un modelo de crítica e todas as demais combinacións posibles.

E non podemos esquecer que este vencello se dá no marco dunha dupla relación de corte historicista do autor coa propia tradición en que se insire: a tradición anterior e a tradición posterior. Quérese dicir que un autor se consolida na medida en que se inclúe como continuador e antecesor dun determinado momento dunha corrente de tradición e que o seu relato (o autor convertido en relato dentro desa tradición) terá que ser un relato que se poida considerar homoxéneo dentro desa tradición. A gloria dun autor está en ser gloria dunha tradición. Non hai outra gloria posible.

Neste sentido, cómpre considerar o feito de que as literaturas minorizadas e propias de sociedades periféricas e miméticas con respecto aos seus centros reais de poder sempre tenderon a ser consideradas como obra de suxeitos individualizados, xenios, neuróticos, solitarios, emprendedores dunha quimera quixotesca e imposible, mais, aínda así, valorable esteticamente antes que produtos regulamentados dunha sociedade con poderes e valores paralelos aos dos seus núcleos administrativos e legais. $\mathrm{O}$ psicoloxismo e a individualización do creador revélanse así como resultados dunha epistemoloxía literaria interesada. E a inclusión ou exclusión da sociedade como posible suxeito que intervén na construto autor aparece como unha parte importante da loita polo sentido en que devén toda concesión de valor. Valórase o xenio individual para desprezar a sociedade e a tradición en que ese autor se insire. 
A primeira tentación é illar a Cunqueiro da tradición literaria galega ou considerar a esta subalterna perante a outra tradición literaria (a española) na que o autor tamén quixo inserirse.

O primeiro que podemos observar é a diferenza notable de resultados: o Cunqueiro elaborado pola ficción crítica galega resulta moito máis poderoso que aqueloutro residual, folclórico e exótico, periférico en calquera caso, moito menos elaborado pola tradición crítica española, se non directamente copiado ou adaptado do Cunqueiro galego. Pódese traducir unha palabra, pódese traducir unha frase, pódese traducir unha obra, pero traducir un autor é imposible. Mesmo traducir o sentido dunha obra dentro dunha tradición é tarefa titánica que esixe aclaracións e esexeses que van moito máis alá das palabras.

Aínda que o A. C. real foi un autor dubitativo, desde o punto de vista lingüístico, a súa construción crítica é claramente galeguista.

A isto axuda, sen dúbida, o feito de que case a totalidade da súa obra poética estea escrita en galego ${ }^{1}$. Certamente, o valor simbólico que A. C. puido ir amoreando dentro do sistema literario español debeuse, sobre todo, ao seu traballo como xornalista e articulista de opinión, mentres que o seu valor simbólico en Galicia se debe fundamentalmente a tres grandes xéneros que Cunqueiro quixo practicar maioritariamente en galego: a poesía, a narrativa e o teatro.

Temos que ter en conta, igualmente, dúas nocións diferentes de tradición: a de raíz gadameriana (a tradición como eternidade, inmenso depósito en que se amorea todo canto algunha vez foi escrito) e a de raíz benjaminiana (a tradición como conflito, unha sucesión de intereses e sentidos que se alternan e que sempre se presentan como redención). Non debemos esquecer que, neste sentido, a tradición literaria galega contemporánea nunca resolveu esta polarización, que fica como un indecidible (Derrida), máxime se anotamos o feito de que nunha cultura diglósica a tradición é sempre conflito e que unha tradición autóctona só se dá como resultado da interferencia dunha tradición allea superposta. E que a tradición autóctona sempre tende a ser considerada como resultado dunha redención.

Deberemos ver aquí en que maneira a fortuna de Cunqueiro ao longo da historia foi moi diversa e non sempre tivo a mesma unanimidade nin a mesma intensidade.

1 Cítese a poesía en castelán. 
Non é igual o Cunqueiro concibido desde o grupo Galaxia que o Cunqueiro forxado desde a Nova Narrativa Galega ou o Cunqueiro de inicios dos oitenta ou o Cunqueiro dos primeiros tempos da Autonomía galega.

Non fai falta explicar que un autor, en canto construto sociolóxica, só ten sentido a partir dunha certa popularidade. E tampouco fará falta explicar que un autor é, antes de máis, unha marca significante que se vai enchendo de sentido ao longo da historia e cuxo valor (Bourdieu) se constrúe como unha crenza. O historiador da cultura e da literatura remítese, pois, á análise desa crenza, o que no noso caso non sería máis que a análise da historia do valor Cunqueiro, ou a actualización dese valor no noso contexto histórico máis inmediato.

\section{6. ÁLVARO CUNQUEIRO: DIGLOSIA E TEXTO}

Tampouco estaría de máis vermos os sentidos que poden tomar as nocións de forza (force) e poder (power) en tanto que enerxía que unha obra amorea e en tanto que valor consolidado que unha obra amorea. Obviamente, estes dous valores non son inamobibles. A forza e o poder dunha obra poden medrar ou minguar segundo as oscilacións das épocas.

E aí sería interesante sinalar os complexos procesos que ligan lingua e temática e estilo nos escritores bilingües que desenvolven o seu labor en contextos de forte diglosia, como é o caso, tal e como ten estudado Antón Figueroa (1988).

De seguirmos ao teórico compostelán, un texto nesta situación verase case obrigado a moverse teoricamente entre estas alternativas: por unha banda, a poetización e derivación cara ao fantástico e cara ao poético, onde o problema parece incidir menos, dada a propia verosimilitude facilmente aceptable do poético, afastamento do mundo referencial a outros espazos e tempos, algo contraditoriamente tamén máis aceptable como verosímil, ou, na outra banda, entrar no problema militantemente e normalizar na ficción a fala dos seus personaxes e dos seus discursos, o que implica problemas de lectura e contradicións pragmáticas, optando daquela polo inmediatamente verosímil a custo de todo o demais e producir discursos posibles en relación co mundo real no que o texto se produce, o que levaría á espectacularización directa da diglosia nos textos. 
Igualmente, seguíndomos con Figueroa (1988), esta posición afectará un posible desprazamento dos sentidos lúdico e carnavalesco do texto, de xeito que a lingua $\mathrm{B}$ pode definirse en termos moi xerais como un carnaval de A, desde onde é imaxinada como contraposición máis ou menos festiva, segundo o momento do proceso, pero, en todo caso, é imaxinada e querida desde este ámbito como provisoria do espazo (un espazo limitado), dentro do espazo que se considera oficial, e un tempo histórico que se quere que sexa tamén limitado e tamén uns tempos ou momentos sociais limitados que lle están destinados e reservados. Ao mesmo tempo, cómpre destacar a tendencia ao monoloxismo. Podemos así sinalar a influencia da folklorización da lingua como unha actitude que trata de recluír o problema lingüístico e a propia lingua a un terreo do típico, do decorativo e, en definitiva, do marxinal. Igual acontecería co contexto rural en que se moven os protagonistas.

Cremos que na obra de Cunqueiro se desenvolve curiosamente, aínda que as súas prácticas textuais poidan ser presentadas como unha constatación do analizado por Figueroa e como unha mostra palpable do triunfo da súa teoría, o efecto contrario: a procura da heteroglosia.

\section{A EVOLUCIÓN POÉTICA DE CUNQUEIRO}

A obra poética de A. C. resulta neste sentido moi ilustrativa. Observamos nel, desde unha perspectiva diacrónica, unha serie de tensións evolutivas que temos referido (2012) como segue:

1. A evolución da poética do autor.

a. Desde o fetichismo verbal á narratividade escénica.

b. Desde o discurso autoglósico ao discurso heteroglósico.

c. Desde a poética do discurso á poética do acontecemento.

2. A ampliación de xéneros literarios no seu rexistro a medida que avanzaba o tempo. Desde o poeta e dramaturgo inicial ao polígrafo final.

3. O conflito entre o poético e o poemático en Álvaro Cunqueiro. Comecemos polo final. En primeiro lugar, é obrigado recoñecer que toda a obra do mindoniense está movida por unha certa procura da emotividade, da 
intensidade lírica e emocional, ou, se se quere e por empregarmos un concepto da terminoloxía clásica (da Poética de Aristóteles), da catarse.

Esta procura, esta vontade, non só se evidencia na súa produción poética senón que, antes ben, nos obriga a reflexionar sobre a dimensión poética do seu teatro, da súa narrativa, do seu articulismo. $\mathrm{O}$ feito de que a lectura, como anteriormente a escrita, leve a cabo unha liberación emocional, unha especie de curación que tería moito que ver, tamén, co emprego terapéutico da palabra en psicoanálise, semella ser o obxecto de procura do autor ao longo de todas as súas páxinas. Así, pois, é o pathos quen fai que lector e autor simpaticen, isto é, etimoloxicamente, compartan os seus sentimentos. Esta igualación emocional semella estar na base da comprensión do pracer estético en Cunqueiro. O importante non serán as palabras, senón o que esas palabras poidan suscitar construíndo emocións no lector. Do mesmo xeito que hai unha retórica da ironía ou do humorismo, Cunqueiro semella tamén procurar unha retórica da emoción ou da sentimentalidade. Esta procura establecerá unha coincidencia nas súas indagacións en calquera dos xéneros en que se exercitou.

A. C. semella ser moi consciente diso que os formalistas rusos denominaron ostranenie; James Joyce, epifaní; Freud, umheimlich; Rilke, o schrecklich; Lacan, joissance. Isto é, do arrebato lírico como unha forma de revelación que tería que ver coa percepción do real como o territorio do inhóspito, sendo, polo tanto, necesario compensalo a través do pracer, estético neste caso. Esta beleza do terrible, do inhóspito, do unheimlich freudiano, conmove coa súa presenza, fainos rir mentres choramos, fainos felices mentres sufrimos, aliméntanos de sentido ao tempo que nos evidencia que nada ten sentido.

Se admitimos o contraste entre o feito (aquilo que ten lugar como resultado da vontade) e o acontecemento (aquilo que ten lugar sen intervención da vontade de quen recibe ou sofre a acción), daquela podemos comprender en que medida a evolución das prácticas textuais de Cunqueiro está vinculada a un desprazamento desde a poética do discurso á poética do acontecemento. Ténase en conta, ademais, que o discurso, como ben sabía o surrealista A. C., ten lugar moitas veces non como resultado dun querer dicir, senón por intervención directa do inconsciente (a través dos lapsus, exabruptos, chistes, xogos de palabras, etc.) Polo tanto, A. C. parece pasar dunha poética pretende como horizonte a procura do acontecemento na linguaxe (tanto desde a perspectiva inicial do escritor como desde a perspectiva 
final do lector) a unha poética xa madura en que é a procura do acontecemento en tanto que unidade do destino humano a que converte en centro da súa poética. Que outra cousa hai neses grandes momentos poéticos como son a representación teatral do Romeo e Xulieta de Shakespeare contra os muros da igrexa de Confront (Donfront en realidade, localidade de Normandía, próxima á fronteira con Bretaña) no final d'As crónicas do Sochantre ou no encontro final entre Tristán e Isolda no relato "Tristán García», por pormos unicamente dous exemplos. A conmoción estética e sentimental de que un acontecemento pode revelarnos de repente o inútil do noso esforzo, do noso voo cego cara á nada.

Isto revélanos, igualmente, a presenza dun conflito nunca resolto en A. C., o conflito entre o poético e o poemático. O poema (o poemático) é o lugar da poesía, pero non só. $\mathrm{O}$ poético pode estar en calquera outro lugar. O poeta, polo tanto, non ten por que ser unicamente un versificador, senón, antes ben, alguén que se nutre no manexo de calquera outra linguaxe. Falar da poesía de Cunqueiro significa falar de toda a obra de A. C. que comprendeu as súas prácticas textuais sub specie poetica. Cremos que esta hipótese de traballo presentaría grandes novidades á revisión crítica de toda a obra do mindoniense.

Coidamos, como xa temos indicado (2012), que esta mudanza está especialmente posta de relevo no tránsito que vai desde o «Rondeau das señoras donas pintadas no Ouso do Vilar, no século xiv, cheirando unha frol», aínda debedor da posición estética inicial, co peso da rima e do ritmo a ser parte consubstancial do sentido que van tomando as palabras, levadas pola sensualidade do discurso, que obriga ao poeta a rimar pais con flores de lis, por exemplo, nun xogo de inxenuidade infantil moi propio dos primeiros libros do autor e vinculado especialmente co seu exercicio do neotrobadorismo, ao «Rondeau da dona enterrada en San Xoán de Badón con dous anxos aos pés», no que o poeta está situado dentro da diéxese (ou cronotopo) da súa ficción narrativa, de maneira que a súa presenza forma parte indispensable da escena que se relata e a voz poética aparece, polo tanto, como unha voz presente e escénica, na medida en que se asemella á voz dun actor que estivese a declamar para un público no escenario dun teatro. $\mathrm{O}$ motivo do monólogo perante unha estatua mortuoria e a evocación metafísica da inutilidade da existencia e da inexorabilidade do paso do tempo dannos conta dunha posición creativa ben diferente. Ambos os dous poemas pertencentes a Dona de corpo delgado (1950). 
Esta dramaticidade, implícita nesta nova maneira de comprender o seu propio discurso, ten moito que ver con dúas cousas: en primeiro lugar, coa presenza dunha narratividade de que estaba carente a súa obra poética anterior, agás uns poucos poemas ("A dama que ía no branco cabalo»...); en segundo lugar, coa apertura a voces que quebran a primacía da voz do autor para convertérense mesmo no principal fío do discurso. Como consecuencia disto, aparecerá unha maior ambigüidade enunciativa (Quen fala en «Eu son Edipo», Cunqueiro ou Edipo?) e unha maior interrelación entre a obra narrativa e dramática, por unha banda, e a obra poética, pola outra. Na conversa/entrevista que lle concede a César Carlos Morán Fraga, poucos días antes de morrer, o 5 de xaneiro de 1981, Cunqueiro sinala que «eu, cando escribía algún libro, pois non podía resistir a tentación de escribir algúns poemas paralelos, de modo que ao lado de Sinbad hai unha serie de poemas..., ben, podémoslles chamar "arábicos". Ao lado de As mocedades de Ulises hai poemas sobre Ulises, sobre Penélope, etc. E sempre fixen uns poemas paralelos ao facer un libro de narrativa». 
